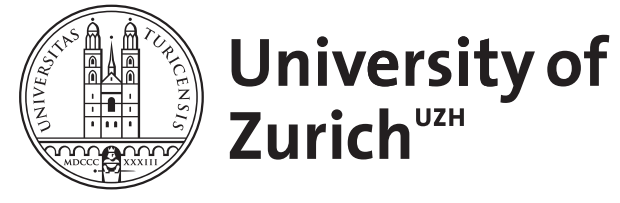

Zurich Open Repository and Archive

University of Zurich

University Library

Strickhofstrasse 39

CH-8057 Zurich

www.zora.uzh.ch

Year: 2015

From control to cooperation - Plea for a new role of IRBs

Christen, M ; Brugger, $\mathrm{P}$

DOI: https://doi.org/10.1016/j.cortex.2015.05.004

Posted at the Zurich Open Repository and Archive, University of Zurich

ZORA URL: https://doi.org/10.5167/uzh-115489

Journal Article

Accepted Version

Originally published at:

Christen, M; Brugger, P (2015). From control to cooperation - Plea for a new role of IRBs. Cortex, 71:415-6.

DOI: https://doi.org/10.1016/j.cortex.2015.05.004 


\title{
From control to cooperation - plea for a new role of IRBs
}

\author{
Markus Christen $^{1, *}$ \& Peter Brugger ${ }^{2}$ \\ ${ }^{1}$ University Research Priority Program Ethics, University of Zurich, Zurich, Switzerland \\ ${ }^{2}$ Neuropsychology Unit, Department of Neurology, University Hospital Zurich, Zurich, Switzerland \\ * Corresponding author: christen@ethik.uzh.ch
}

In his essay, Johnathan Baron provides a concise overview of problems regarding human-subject protection through IRBs. To our understanding, the listed fallacies inherent to Institutional Review Boards (IRB) point to major structural problems in the current way to ensure ethical research standards. But the reasons for these problems go beyond lack in competence in decision theory or statistics some if not most members of IRBs may have. The true problem, in our opinion, is the assumption that the primary role of IRBs is that of a "watchdog" of researchers, which does not seem to be questioned by Baron. At least his suggestion that IRBs should change their emphasis from prior review to rule enforcement implies at least tacit agreement with this assumption.

To our understanding, a reconsideration of the role of IRBs should take into account the following important changes that refer to research involving human subjects: First, we currently experience a remarkable change regarding the involvement of subjects in research in general. Increasingly, they become active partners or even drivers of research. For example, participants recruited using Amazon Mechanical Turk review the "requesters" (which are, among others, researchers posting, e.g., behavioral web experiments) in various respects (Irani \& Silberman 2013). Other participants even self-organize in conducting research, a behavior that poses significant challenges for the current IRB system because no formal principal investigator of such studies can be named (Vayena \& Tasioulas 2013). Second, given that information technology makes it increasingly easier to recruit participants (as the example of Amazon Mechanical Turk demonstrates) or to get access to interesting data (e.g., through social networks), the costs of performing research will decrease and the number of studies requiring IRB approval because they involve human subjects or personal data may soon overburden the capacities of the system. For example, although the current law in Switzerland requests the cantonal review boards to reach a decision within 30 days after acknowledgment of receipt of an application, no IRB is currently able to comply with this time limit. Related to this is a third problem that may be of particular relevance for European universities. The so-called Bologna system requires research-based Master theses also in medicine. In Zurich alone this means that up to 300 students per year have to conduct research involving in many cases human subjects - most of them are rather small and simple studies, yet each of these requires ethical approval. Given the short time available for such studies, the willingness of researchers to support them has decreased. This illustrates how watchdog IRBs clash with education rules.

Blaiming IRBs alone does not solve the problem, however. Proposals submitted to IRBs often have methodological flaws that make an evaluation difficult. At least in Switzerland, this is a common reproval from the side of IRBs in case a submission got rejected or needs improvement. Baron seems to 
imply that these kinds of methodological issues should not be a matter review boards should be concerned with. That IRBs do uncover methodological flaws is one thing, much worse seems that they currently do not provide support in how to improve methods.

In summary, a "watchdog IRB system" is likely to reach its capacity limit soon, will have problems to deal with novel forms of participant-researcher interactions and nevertheless will have to find a way to respond to methodological flaws contained in at least some applications. To our understanding, the IRB system will need a fundamental change away from a "control" towards a "cooperation" focus that involves all relevant stakeholders - researchers, IRB members and study participants.

We believe that the following principles should accompany such a change in focus: First: bad science is an ethical issue as well, because it waists time, money and other resources. This basically means that methodological issues of research should not be outside of the scope of an IRB, but they should become a necessary component when assisting researchers in preparing their research proposals. This requires a change in mindset of IRBs: Their role should not be about protecting participants from researchers in the first line. But it should be about ensuring high-quality research from which researchers, participants and society can profit the most. For example, IRBs could host databases of best practice examples in ethically conducted research. This will also require changes in the internal organization of scientists working at an institute of faculty. The formation of internal "pre-review" boards of experienced scientists might be necessary to check for methodological flaws and ethical shortcomings.

Second, we should use the possibilities of today's information technology for creating a collaboration infrastructure in research. Social networks like Facebook or Linkedln provide examples of how people can interact and collaborate in private and business matters - why not create a similar type of social network that links researchers, participants and IRB members for participant recruitment, exchange of information, and even some sort of "crowd review"? We have recently submitted a large European proposal that aims to create such an infrastructure.

Finally, universities should be more aware regarding the interlinking of the various ethical issues that accompany research and they should respond to that on an institutional level. Currently, institutions handle issues like the protection of research participants, scientific misconduct, or mobbing, as separate problems. However, these apparently different issues may be more interlinked than commonly thought. Thus, the work of IRBs should be seen as an element of a broader endeavor, namely to improve the overall "ethical climate" in a research facility.

There is certainly much more to say regarding all of these points. But we think that the time has come to refocus aims and interaction of IRBs with all relevant stakeholders - researchers and participants. Otherwise, the system will soon suffer "death by bureaucracy".

\section{References}

Irani LC, Silberman MS (2013): Turkopticon: Interrupting Worker Invisibility in Amazon Mechanical Turk. In: Proceedings of the SIGCHI Conference on Human Factors in Computing Systems, Paris, April 27 - May 2 2013, pp. 611-620 
Vayena E, Tasioulas J (2013) Adapting Standards: Ethical Oversight of Participant-Led Health Research. PLoS Med 10(3): e1001402 